\title{
Are We Doing What We Claim?: A Portfolio Approach to Program Performance Assessment
}

\author{
Ron Pigott, Bill Karr \\ Texas Tech University
}

The accreditation self-study looms on the horizon, and your department needs to provide supporting evidence that it is achieving its goals. A large part of the effort required to accomplish this task is to show that the department is properly assessing its performance related to the objectives generated by the department goals. The Engineering Technology Department of the College of Engineering at Texas Tech University faced the completion of this accreditation requirement last year and set out to develop an approach that would provide ongoing assessment of the department goal-based objectives and supply more than adequate resources for the completion of any accreditation requirement associated with verifying that those objectives were met.

The Beginning Stages

Several years ago, the engineering technology faculty reviewed with its Industrial Advisory Board (IAB) the performance measures it had in place and the new TAC/ABET requirements. While the criteria still retained the specificity and credit hour requirements, the new requirements also stated that programs must demonstrate achievement towards goals through various methods such as outcomes assessments, graduate career performance and employer feedback. Programs were also required to demonstrate continuous improvement. Given that we expected TAC/ABET to move toward the same criteria as EAC/ABET (a completely outcomes assessment based approach), we decided that we needed to do a better job of specifying our goals and objectives and of measuring our performance against those objectives. Accordingly, a Quality Management Workshop for faculty and IAB members was organized. The workshop was facilitated by Manny Torres and Mack Thorn from the Texas Department of Transportation. After working as a group to identify our goals and objectives, the group (faculty and IAB members) was divided into teams to work on generating details such as expected outcomes, implementation strategy, assessment methods, and performance criteria. As a result of that initial effort, six department goals were identified and adopted by the department faculty (Figure 1). The goals were then addressed by goal-based objectives to reflect the intentions of the department and to coordinate the department's goals with the then existing criteria of the TAC of ABET.

The objectives were divided into two groups with problem solving, communications, technical knowledge, computer skills, business knowledge, professional attributes, and time management objectives related to the development of students within the department as one set, and research and publications objectives related to the department's development of faculty research and publication credentials as the other set. (Figure 2). Although the objectives can be neatly divided into these two areas, it quickly became clear that placing single objectives with 


\section{Department Goals}

1. To be recognized by employers and the general public as being number one in the state of Texas in providing graduates who have immediately useful engineering skills applicable to a global market place.

2. To provide high quality engineering technology programs with appeal to a broad range of students including traditional students, under represented populations, and the by-passed learner, so that educational opportunities are provided to a greater cross-section of the state's population.

3. To provide programs that reflect the needs of industry worldwide.

4. To provide the support necessary for students to develop their intellectual capacities, technical competencies, and social responsibilities.

5. To have faculty who perform independent applied research or consulting that will add depth, quality, and practical experience to the department.

6. To continuously improve the programs in order to correlate with the type and rate of change taking place in the global marketplace.

Figure 1

one particular goal would be impossible. Because the objectives would not neatly fall in line with a single goal, the assessment of the goals was problematized by the difficulty of placing a measurable objective in a verification association with the goal. It was at this point in the history of the process that the department decided to look at using multiple assessment methods to verify the attainment of individual objectives and to create a matrix of data collection and assessment strategies. What the department now views as a "Program Assessment Portfolio" was developed in hopes of providing acceptable levels of assessment to verify department performance toward the attainment of department goals.

Objective Area

Problem Solving:

Communications:

Technical

Knowledge:

Computer Skills:

Business Knowledge:

Professional

Attributes:

\section{Full Objective}

Students will obtain an ability to solve engineering problems in practice by applying fundamental knowledge of mathematics, science and engineering. Modern engineering techniques, skills, and tools will be used, particularly recognizing the role that computers play in engineering.

Students will gain the ability to effectively communicate technical and non-technical issues through both verbal and written skills sufficient to permit them to apply those skills in professional practice. Attention will be paid to the skills, and tools commonly used in modern communications, particularly recognizing the role of computers.

Students will obtain a broad-based basic knowledge of engineering. They will also achieve technical competence in their core discipline. This knowledge base will provide students with the foundation required for them to solve engineering problems in practice, and will also enable them to pursue life-long learning.

Graduates from the Engineering Technology Department will be computer literate. They will have a basic understanding of the uses of the operating system (WIN 95/98, how to format a disk, install programs, defragment drives), a word processor (spell checking, grammar checking, proper format, inserting graphics and tables), a spreadsheet (programming, graphing), email (attachments), using the Internet for research and information gathering (downloading files, uploading files), programming (logic, sequencing, looping, conditional statements), and presentation tools (slide shows, graphics, linking).

Students will gain knowledge of basic business/project management skills sufficient to permit them to apply those skills in practice to the management of engineering projects. Modern business management techniques, skills, and tools will be used, particularly recognizing the role that computers play in engineering.

Throughout their college career, students will be encouraged to develop a strong work ethic, and to be self-motivated to achieve excellence in whatever field they work. Part of a student grade in every class will be for professionalism, which will include professional 
attributes.

Time management: $\quad$ Students will obtain an ability to effectively schedule and manage their time by being exposed to proven time management techniques through their course work in Engineering Technology. Students will apply time management criteria to school projects to establish habits of effective time management in practice. Current scheduling and time management techniques, skills and tools will be used with an emphasis on the role that computers play in engineering.

Research: $\quad$ Increase the amount of applied research performed by the department. Have every faculty member in the department involved in at least one applied research project.

Publications: Increase the number of technical papers published by the department' faculty.

Figure 2

When the old TAC/ABET criteria were in place, an institution could almost wait until the year before the visit to start working on preparation for the visit. This is not to say that institutions could ignore the criteria for six years at a time. Programs had to be reviewed and updated on a continuing basis and the criteria had to be checked to make sure that when the curriculum was changed there were still enough "beans" in each pile to satisfy the program requirements. However, the bulk of the work required for preparation for a visit would be in the year preceding the visit. With the proposed criteria to be used for pilot visits conducted during Fall 2001, this is no longer the case. With the outcomes assessment approach, departments must continuously work on verifying their performance toward attainment of their objectives. To aid in this ongoing effort, the Department of Engineering Technology at Texas Tech established the "Program Assessment Portfolio." While this is not yet fully implemented, it is expected that the portfolio will have information added to it on an ongoing basis. The department is currently working on establishing a culture where faculty think in terms of collecting data to show how objectives are being met. This is no simple task, and the subject of assessment is being reviewed periodically at faculty meetings in an effort to establish this culture. The subject is also being reviewed at IAB meetings with emphasis on continuous improvement.

In looking at performance against objectives, it must first be recognized that no single assessment method is perfect. The Department of Engineering Technology at Texas Tech has therefore established multiple assessment instruments in order to achieve a reliable measure of accomplishment, hopefully, without overloading faculty. In the past the department had done the traditional assessment methods such as alumni surveys, employer surveys, graduate surveys, exit interviews, and so on. In looking at the department's objectives it was apparent that other types of assessment would be necessary.

From published literature relating to EAC/ABET accreditation criteria, it would appear that many engineering programs are placing a lot of emphasis on passing the Fundamentals of Engineering (FE) Exam. For many years the Department of Engineering Technology at Texas Tech has been teaching a fundamentals review course and has encouraged its students to take the FE Exam. However, the department was reluctant to put this assessment method in someone else hands. It therefore decided that the first time pass rate on its own fundamentals type exam would be a better way to make this assessment. Passing this exam is a requirement for graduation.

In assessing our student's computer skills, we decided that in this case a self-assessment would be satisfactory. The self-assessment could be taken via the Internet. The problem in this case is that we are comparing incoming freshmen with outgoing seniors. In the case of computer 
skills, it is our perception that the computer skills of incoming freshmen are getting better all the time. Thus the assessment as it stands may underestimate the value added by the department. Nonetheless, the assessment has provided some useful information. For example, it was found that there was a significant difference between program options in the area of computer programming skills. The electrical/electronics students scored highest with construction students scoring lowest. This result might have been expected, but after some review, we decided that we needed to make some changes in the computer programming experiences for our construction students. As time goes on, it is expected that this assessment will become more accurate.

Structuring the Portfolio

A large part of the motivation for this self-assessment structure is the accreditation requirement faced by the Engineering Technology Department. Under the current scheme, The ABET accredits Engineering Technology through the criteria established by TAC. TAC is currently developing its student and graduate criteria known as Criteria 1 for the year 2000. This set contains twelve criteria that must be addressed by the programs seeking accreditation through ABET. The Engineering Technology Programs at Texas Tech University considered addressing the assessment of the program in light of the new criteria to be a priority. The twelve criteria listed below are from the Proposed Engineering Technology Criteria 2000.

\begin{tabular}{|l|l|}
\hline a. & Demonstrate an appropriate mastery of the knowledge, techniques, skills and modern tools or their disciplines \\
\hline b. & $\begin{array}{l}\text { Apply current knowledge and adapt to emerging applications of mathematics, science, engineering and } \\
\text { technology }\end{array}$ \\
\hline c. & Conduct ,analyze, and interpret experiments and apply experimental results to improve processes \\
\hline d. & Apply creativity in the design of systems, components, or processes appropriate to program objectives \\
\hline e. & Function effectively on teams \\
\hline f. & Identify, analyze, and solve technical problems \\
\hline g. & Communicate effectively \\
\hline h. & Recognize the need for and possess the ability to pursue lifelong learning \\
\hline i. & Understand professional, ethical, and social responsibilities \\
\hline j. & Recognize contemporary professional, societal, and global issues and are aware of and respect diversity \\
\hline k. & Have a commitment to quality, timeliness, and continuous improvement \\
\hline
\end{tabular}

Table 1

In order to establish that the department's assessment methods would indicate progress toward attaining acceptable performance in all areas, three matrices needed to be created. One matrix was required to show the relationship between the department's goal based objectives and the ABET criteria, a second matrix was required to show the relationship between the ABET criteria and the assessment methods, and a third was required to show the relationship between the department objectives and the assessment methods. The matrix shown in Table 1 was constructed to show the relationship between department objectives and the ABET criteria. The department objectives are represented in the columns and the ABET criteria are represented in the rows. It is important in this matrix that the distribution of goal and criteria intersects be fairly uniform in number to indicate that the department's objectives were in significant agreement with the ABET criteria

The matrix shown in Table 2 shows the relationship between the ABET criteria and the department assessment methods. The rows of the matrix list the student criterion from the TAC 
of ABET. The columns list the assessment methods constructed by the department to be included in the Program Assessment Portfolio. The shaded intersect areas of the matrix indicate that the criteria on that row is being addressed by the assessment method listed in the intersecting column. Our purpose was to ensure that each criterion was adequately assessed. The highest assessment number achieved was for criteria "b" with 9 assessment activities, and the lowest assessment number achieved was for criterion "d" with 3 assessment activities. Although each criterion did not receive an equal application of assessment methods, we believe that the distribution of methods and the nature of the methods used results in an adequate assessment of the objective under the demands of Criterion 1. As is common in portfolio assessment strategy, each assessment method is not equally represented among all factors nor does each assessment method carry equal weight in the final evaluation.

\begin{tabular}{|c|c|c|c|c|c|c|c|c|c|c|c|c|c|}
\hline \multicolumn{14}{|c|}{ ABET Criterion/Assessment Method Matrix } \\
\hline \multirow[b]{2}{*}{ (Students and Graduates) Criterion 1} & \multicolumn{13}{|c|}{ Assessment Method } \\
\hline & 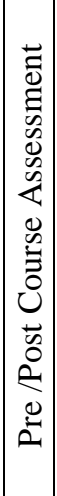 & 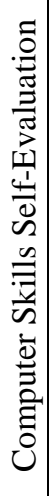 & 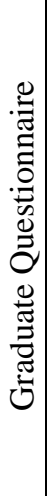 & 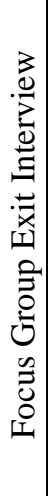 & 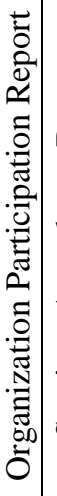 & 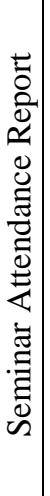 & 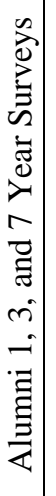 & 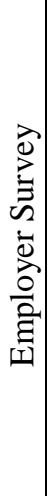 & 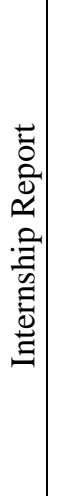 & 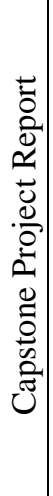 & 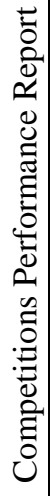 & 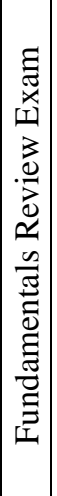 & 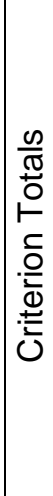 \\
\hline $\begin{array}{l}\text { a. Demonstrate an appropriate mastery of the knowledge, } \\
\text { techniques, skills and modern tools or their disciplines, }\end{array}$ & & & & & & & & & & & & & 8 \\
\hline $\begin{array}{l}\text { b. Apply current knowledge and adapt to emerging applications } \\
\text { of mathematics, science, engineering and technology, }\end{array}$ & & & & & & & & & & & & & 9 \\
\hline $\begin{array}{l}\text { c. Conduct, analyze, and interpret experiments and apply } \\
\text { experimental results to improve processes, }\end{array}$ & & & & & & & & & & & & & 4 \\
\hline $\begin{array}{l}\text { d. Apply creativity in the design of systems, components, or } \\
\text { processes appropriate to program objectives, }\end{array}$ & & & & & & & & & & & & & 3 \\
\hline e. Function effectively on teams, & & & & & & & & & & & & & 5 \\
\hline Identify, analyze, and solve technical problems, & & & & & & & & & & & & & 6 \\
\hline g. $\quad$ Communicate effectively & & & & & & & & & & & & & 8 \\
\hline $\begin{array}{l}\text { h. Recognize the need for and possess the ability to pursue } \\
\text { lifelong learning, }\end{array}$ & & & & & & & & & & & & & 4 \\
\hline i. Understand professional, ethical, and social responsibilities, & & & & & & & & & & & & & 9 \\
\hline $\begin{array}{ll}\text { j. } & \text { Recognize contemporary professional, societal, and global } \\
\text { issues and are aware of and respect diversity, and }\end{array}$ & & & & & & & & & & & & & 5 \\
\hline $\begin{array}{l}\text { k. Have a commitment to quality, timeliness, and continuous } \\
\text { improvement. }\end{array}$ & & & & & & & & & & & & & 8 \\
\hline Assessment Portfolio Totals & 4 & 3 & 5 & 6 & 6 & 5 & 4 & 9 & 7 & 7 & 8 & 5 & \\
\hline
\end{tabular}

Table 2

Proceedings of the 2001 American Society for Engineering Education Annual Conference \& Exposition Copyright $\odot$ 2001, American Society for Engineering Education 
Table 3 shows the relationship between the department objectives and the department assessment methods. Departmental objective areas are represented in the columns and the assessment methods are represented in the rows. Again, the shaded areas indicate the points of intersection between the objectives and the assessment methods. The numerical values in this matrix indicate that each objective was well covered by the department assessment methods.

\begin{tabular}{|c|c|c|c|c|c|c|c|c|}
\hline \multicolumn{9}{|c|}{ Department Objectives/Assessment Methods Matrix } \\
\hline \multirow[b]{2}{*}{ Assessment Method } & \multicolumn{8}{|c|}{ Department Objective Areas } \\
\hline & 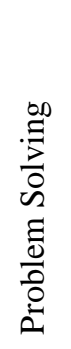 & 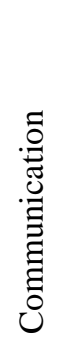 & 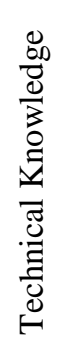 & 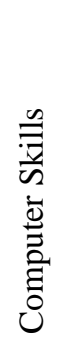 & 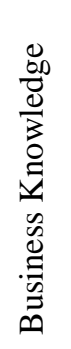 & 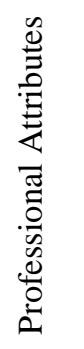 & 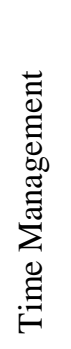 & 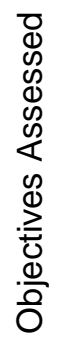 \\
\hline Pre /Post Course Assessment & & & & & & & & 4 \\
\hline Computer Skills Self-Evaluation & & & & & & & & 2 \\
\hline Graduate Questionnaire & & & & & & & & 3 \\
\hline Focus Group Exit Interview & & & & & & & & 2 \\
\hline Organization Participation Report & & & & & & & & 5 \\
\hline Seminar Attendance Report & & & & & & & & 2 \\
\hline Alumni 1,3 , and 7 Year Surveys & & & & & & & & 6 \\
\hline Employer Survey & & & & & & & & 7 \\
\hline Internship Report & & & & & & & & 7 \\
\hline Capstone Project Report & & & & & & & & 7 \\
\hline Competitions Performance Report & & & & & & & & 6 \\
\hline Fundamentals Review Exam & & & & & & & & 2 \\
\hline Total Objectives Assessed & 8 & 6 & 7 & 8 & 8 & 10 & 6 & \\
\hline
\end{tabular}

Table 3

Existing Assessment Methods

As we set about to develop the assessment methods for the Program Assessment Portfolio, we turned first to those assessment methods that were currently in place. Examination revealed that the existing methods of evaluating the department's performance could be divided into formal and informal methods. The formal methods had clear objectives, document sources, and were used to generate reports for the department. Informal methods were not part of the information collecting strategy for the department and existed more as common knowledge throughout the department. Option coordinators and other faculty members were aware of the performance of the program as it related to these methods but documentation of performance was not maintained and the information was generalized when it was reported.

Existing Formal Assessment Methods

The assessment methods that belonged in the formal category were the graduate questionnaire, alumni surveys, employer surveys, internship reports, fundamentals review course 
examinations, and capstone project reports. The formal methods had been used by the department for some time and were well established as information generating sources for department decision-making and for inclusion in regional accreditation self-studies. The informal methods included focus group exit interviews, competitions performance information, organization participation information, and seminar attendance information. None of these methods generated documents that could be used to support accreditation reports, but the department, through the office of the department chair, was aware of the information and utilized it in formulating department decisions and in supporting and defending the performance of the department. The two entirely new assessment methods that were generated for the program assessment portfolio were the pre /post course assessment and the computer skills selfevaluation. It is somewhat unfair to describe these two methods as entirely new because the issues were addressed in some form through course evaluations, student grades, and other evaluation methods, but because we generated entirely new activities within the department for collecting hard data, we consider them to be new methods for assessing performance. In order to understand fully the scope of the program assessment portfolio, it is necessary to examine each assessment method briefly.

The department distributes a questionnaire to all graduating students in the semester in which they are scheduled to graduate. The department chair maintains the information recorded on the questionnaire form and is responsible for the interpretation and use of the data. The Program Assessment Portfolio requires that the questionnaire be updated on a regular basis so that it reflects the true attitude of the students as they graduate. No major changes were required to integrate the graduate questionnaire into the Program Assessment Portfolio.

The Texas Tech University, Research Services Office conducts alumni surveys at one, three, and seven-years after graduation. The survey collection consists of a general institutional survey, a College of Engineering Survey, and an Engineering Technology Department Survey, which has only been active for one survey cycle. Currently, the responses to the department survey have been slow, but over time, we expect this method to generate some very usable data. Because we have been receiving data from the general survey on a regular basis we did not consider this method to be new, but we were required to construct a survey form that reflected the demands of Engineering Technology Criteria 2000.

The most formal of the existing methods used by the department was the employer survey. This survey was distributed to graduates of the department at their workplace and consisted of a series of questions to be answered by the employer. The response was not overwhelming but it did produce enough information to develop an influence on the curriculum and the practices of the department. The survey has been updated to reflect the demands of Engineering Technology Criteria 2000, and it will continue to be distributed on a regular basis. The results from the survey are collected in an MS Excel spreadsheet and manipulated to produce various reports.

Option coordinators have been responsible for collecting data on their students involved in department internship activities for some time, but the information collected tended to stay in the option coordinators' possession. The internship report is generally the same document as the Employer Survey and was also amended to reflect the demands of Engineering Technology 
Criteria 2000. Data collection methods are the same as for the employer survey with the results kept in the assessment portfolio database

The fundamentals review exam taken by all students is administered after the fundamentals review course and historically has been incorporated into the student's grade structure. Under the portfolio method, student grades are not part of the overall assessment of the department performance, but this is one case where the student performance indicator is directly applied to the database. Once the fundamentals exam is completed the results are recorded in that students section of the assessment portfolio database. The recording of exam results in the database was the only change required.

The Capstone Project Report was originally recorded as part of a student grade, but within the assessment portfolio the individual student scores can be recorded as a tool for assessing the overall effect of the department on student performance. Students are evaluated on a rubric developed by the department that is designed to evaluate the objectives associated with the capstone project. The data collection is very straightforward with each student's performance being recorded in the assessment portfolio database. Existing Informal Assessment Methods

Several previously existing informal assessment methods have now been formalized and used in the assessment portfolio. It is safe to assume that most departments have a number of informal assessment strategies. The difficulty in using these strategies to support assessment reports is that the results are often randomly collected and are not recorded in a form that can be incorporated into an ongoing report structure. In our department we have identified four such strategies marked by several common features. First all of these activities involve students in non-credit activities. Second, the activities do not require regularly scheduled participation by students. Third the faculty responsible for tracking performance indicators is not formally assigned. We have attempted to formalize these activities but not structure them to the point that they become intrusive for the faculty responsible.

The first of these activities is the focus group exit interview. The department chair conducts informal interviews with the graduating students at the end of the regular semesters to determine the general attitude of the students toward the department and the students' evaluation of the education and preparation received in the students' course of study. The methodology has not changed. Because graduating students are poised between student and alumni worlds and can offer a unique view of the department's performance, the interview is conducted in a fairly casual manner. The results of the interviews is maintained by the department chair and quantified for inclusion in the assessment portfolio database. The only changes required were the quantification scale and the inclusion in the database.

The next three activities are very closely related in structure and will be handled as one category of activity. Competition activities, organization participation and seminar attendance are part of the overall education of our students, but maintaining performance records on these activities can very easily become part of the department lore. In order to make the results of student participation in these activities part of the assessment database it was necessary to formalize the record keeping and move the results to a more permanent form. In the past the 
option coordinators have kept track of the involvement of students in these activities, and the recording of results has been left up to the individual coordinator. Under the portfolio approach, the option coordinators are required to either report students results to the department secretary for inclusion in the database or to perform the input themselves. Changes required to formalize the reporting of these three activities were minimal. No additional forms were necessary and the only true change was that information that had once been in someone's head now resides in the assessment portfolio database.

New Formal Assessment Methods Used in the Portfolio

As we began to examine the requirements of the new criteria, we realized that two areas of department performance under increasing scrutiny were the performance of courses students were required to take and the level of student computer skills. As a result of this observation we decided to implement two new assessment strategies. Both strategies add additional layers of assessment to areas that were covered in some form by existing approaches, but we decided that the new strategies would strengthen our ability to show satisfactory performance in both areas.

Pre-course/Post-course Assessment

Traditionally, institutional and department student course evaluations are used as justification for the performance ratings of courses and instructors. Although the evaluation method has value, it is clear that there are several flaws in the validity of student-based evaluations of course content and performance. The most noticeable flaw in the student evaluation of course and instructor performance is the lack of objectivity. In order to achieve a more valid assessment of course and instructor performance, we devised course assessment instruments that are administered to the students in individual courses at the beginning and end of each semester.

Producing the pre-course/post-course assessment instruments and strategy began as a very small effort. Initially only one course was assessed to determine the best procedure for structuring the process. A general computing course was selected and the first instrument was developed. After the pre-course evaluation was performed, the results of the student responses were examined to determine where the flaws in the approach might exist. After waiting for the semester to near conclusion, we administered the post-course assessment. By looking at the relative gain in student performance on each indicator, we were able to ascertain the ability of the course to affect student learning and change.

The assessment instrument itself is a fairly benign document. The general guidelines for the pre-course assessment and post-course assessment instruments are identical. The Department desired to know: 1) if students moving through the courses had the necessary background to be successful without remediation, 2) are the majority of students making the knowledge gains the course is intended to create, and 3) what improvements in content and approach could make the course perform better.

Computer Skills Self-assessment 
A second area of assessment that was added to the portfolio was a computer skills selfevaluation instrument. This instrument covers areas of computer skills determined by the department to be essential to satisfactory performance in the field of engineering technology. The department was surveyed to determine which skills were essential to satisfactory performance. When the results of the survey were examined we determined that skills in the areas of using the WIN 95/98 operating system, using a word processing program, using presentation tools, using e-mail, using the Internet, using TK Solver, and using a spreadsheet program were departmental requirements.

The instruments used to determine student performance in computer skill acquisition is a student self-assessment survey administered to both entering and graduating students in any given semester. Although self-assessment scales are open to a variety of interpretations, we determined that the individual student's comfort level would be a good indicator of competency. There is no performance requirement on the survey, so all data is self-reported and not based on a performance grade.

\section{Information Management}

The amount of information collected in an assessment portfolio can become quite large and difficult to manage without using a database structure that allows for easy report generation. We are currently using Micro Soft Access as our database, which allows us the flexibility to create an individual table for each assessment activity and to generate reports based on those tables that reflect our assessment objectives. The practice of data collection has been identified for each objective area, and the staff or faculty responsible for the data entry has access to the database based on the individual assessment activity or program option. Option Coordinators can produce assessment reports based on the performance of students within their particular option. This gives the department the ability to essentially create an assessment portfolio based on individual options within the assessment of the entire department. We see great value in the ability to easily get an overview of the entire department's performance, while at the same time being able to generate an assessment of each option within the department.

It is the ambition of the Department to eventually place the Assessment Portfolio Database online where access will be easier for the faculty and staff with input responsibilities to access the information. Non-sensitive records could be configured to show the assessment progress of the department and used in recruitment and student information services.

\section{Conclusion}

The entire process of assessing the performance of a department is both complex and demanding. The accreditation agencies are requiring increasing diversity in the assessment measurements and in the way those measurements are constructed. The department assessment portfolio provides a means for both managing and reporting multiple input to the assessment process and at the same time giving department administration the ability to customize the reporting of that information. The reports generated can be structured to reflect the mission of the department, the requirements of accrediting agencies, and the internal assessment needs of the programs within the department. 
Although the concept of a department assessment portfolio is structurally simple it will require a commitment to developing or altering current assessment practices to correctly reflect department goals and objectives. In addition to the necessary changes in assessment practices, the department will need to commit to the development of faculty and staff to maintain the assessment portfolio. We believe the assessment portfolio approach brings several positive elements to the historically difficult assessment process while, at the same time, allowing the department full control over the structure and scope of the assessment process. The key to the success of the Program Assessment Portfolio approach is in the distribution of the assessment process over many goal based assessment practices.

By distributing assessment process over numerous student and department performance measures, the risk of narrowly defining department progress is reduced. The performance of the department in developing student computer skills is not linked to one class or assessment but is extracted from many unrelated measures of student outcomes. Some of the outcomes are measured in the traditional test format at the time of instruction. Other outcomes are gathered from student performance that is not associated with traditional classroom based measures. By combining both in a matrix, the assessment of the department's performance indicators should produce a greater degree of accuracy and validity.

The distribution of the assessment practices provides a constant stream of information about the department's performance that allows department administrators to maintain an ongoing assessment overview instead of a "once in four years" sketch. The traditional rush to satisfy accreditation requirements can place a department in an ethical bind. We in no way contend that any department would knowingly submit false information, but in the rush to collect assessment information, mistakes can be made. The ongoing assessment of the department's performance creates an environment of knowledge and understanding that fosters two very valuable outcomes. First, the department administrators are in touch with the department's performance in terms of the department goals and objectives on a continual basis. Instead of making large and disruptive changes to department practices on the receipt of an accrediting agency's report. Second, changes to the department's practices can be mandated on an incremental basis. We believe that altering the practice of a department and its faculty will be more successful if entered into with the support of the faculty and staff following discussion that allows for full disclosure by the department administration and solicited input from the faculty and staff. Under the "every four years" approach, required changes to department practices are usually entered into under some pressure and a " we must do this whether we like it or not" feeling. The pressured environment offers less opportunity for all concerned parties to be involved in the decision making process, and as a result the decisions and actions may not be well received. By continually assessing performance, it is hoped that all contributing persons will gain an enhanced view of overall department performance and a better understanding of and involvement in their individual contribution.

References

Dietel, R.J., Herman, J.L., \& Knuth, R.A. (1991) What does research say about assessment? NCREL, Oak Brook. 
Education Week on the Web (1999, January 11). Quality counts '99. Retrieved December 12, 2000, from the World Wide Web: http://www.edweek.com/sreports/qc99/exsum.htm

Education Week on the Web (1999, January 11). Ten recommendations for reporting school results to the public. Retrieved December 10, 2000, from the World Wide Web:

http://www.edweek.org/sreports/qc99/opinion/aplus1.htm

Fetler, Mark E., (1994,). Carrot or stick? how do school performance reports work? Education Policy Analysis Archives 2 (13). Retrieved November 22, 2000, from the World Wide Web: http://olam.ed.asu.edu/epaa/v2n13.html

Roeber, E. (1992). 1. Developing the comprehensive assessment system: A. top down, B. bottom up, C. both, D. none of the above. Paper presented at the 1992

Education Commission of the States Conference on Large-Scale Assessment.

Roeber, Edward (1995). Emerging Student Assessment Systems for School Reform. ERIC

Digest. Retrieved November 4, 2000, from the World Wide Web:

http://ericae.net/edo/ED389959.htm

Shavelson, Richard J. , McDonnell, L. \& J. Oakes (1991). Steps in designing an indicator system. Practical Assessment, Research \& Evaluation, 2(12). Available online:

http://ericae.net/pare/getvn.asp

\section{RON PIGOTT}

Dr. Pigott is a professor and the chairperson of the Texas Tech University Department of Engineering Technology, 1991. Dr. Pigott received his Ph.D. from Pennsylvania in 1975

\section{BILL KARR}

Bill Karr is a Ph.D. candidate in the Technical Communication And Rhetoric program at Texas Tech University and serves as the staff technical writer for the Engineering Technology Department. 